\title{
DERADIKALISAI AGAMA MELALUI INTERNALISASI PENDIDIKAN INKLUSIF-MULTIKULTURAL
}

\author{
Zahra Billahi Rizqi Ramadhani \\ Tadris IPS IAIN Jember \\ zahrabillahi9@gmail.com \\ Depict Pristine Adi \\ Tadris IPS IAIN Jember \\ depict.socialedycation@gmail.com \\ Zamhakiyullah \\ Tadris IPS IAIN Jember \\ zamhaqi@gmail.com
}

\begin{abstract}
Abstrak
Tujuan penelitian ini yaitu beurtujuan ntuk mendeskripsikan upaya membangun kesadaran inklusif-multikultiral untuk deradikalisai agama. Terdapat beberapa aksi di Indonesia yang menjadi bukti konkrit bahwa penggunaan pendekatan keamanan saja tidak cukup efektif untk mengatasi kasus terorisme hingga ke akarakarnya. Oleh karena itu, berbagai pendekatan digunakan untuk penanganan aksi teroris dan radikal Islam. Salah satunya adalah dengan program deradikalisai dengan pendidikan Islam inklusif multikultural. Pendidikan Islam bernuansa inklusif multikultural dalam penelitian ini yaitu sebuah wujud tantangan bagi pendidikan Islam untuk bagaimana meminimalisir aksi teroris dengan pendekatan inklusif, dan multikuktral yang akhirnya berpengaruh kepada kehidupan masyarakat, tumbuh pemahaman keagamaan yang toleran,serta melakukan reorientasi visi pendidikan yang berbasis eksklusif-monolistik dengan penguatan visi misi pendidikan agama Islam. Dalam hal ini, maka mereka perlu memperhatikan faktor kurikulum, pemdidik, dan strategi pembelajaran yang diterapkan pendidik. Upaya deradikalisai Islam dalam rangka membangun inklusi multikultural perlu menajdu kajian yang mendalam, dengan gerakan review kurikulum diberbagai tingkatan pendidikan. Peneliti menggunakan metode penelitian berjenis kajian kepustakaan yaitu menghimpun informasi yang relevan dengan topic yang menjadi objek penelitian. Hasil atau kesimpulan dari penelitian ini yaitu upaya yang efektif dalam membangun deradikalisasi agama adalah dengan lembaga pendidikan, melalui reorientasi visi pendidikan agama yang berbasis eksklusif monopoli ke arah penggunaan inklusi-multikultural.
\end{abstract}

Kata Kunci: deradikalisasi agama, pendidikan inklusif-multikultural 


\title{
AL-ADABIYAH: Jurnal Pendidikan Agama Islam
}

\begin{abstract}
The purpose of this study is to describe efforts to build an inclusive-multicultural awareness for the religious deradicalitation. There are still many acts of terrorism in Indonesia that constitute concrete evidence that the use of a security approach alone is not effective enough to deal with cases of terrorism to its roots. Therefore, various approaches are used to deal with terrorism and Islam ic radicalism, one of which is through a deradikalisai program through an inclusive-multicultural Islam ic education. Islam ic education with multicultural inclusive nuances in this research is a form of challenge for Islam ic education in how to minimize terrorist acts with an inclusive, and multicultural approach so that in the end of society life grows a tolerant religious understanding, and reorients the vision of education based on exclusive-monolistic basis strengthening the vision and mission of Islam ic religious education. In this case, they need to pay attention to curriculum factors, educators, and learning strategies used by educators. Efforts to deradikalisai Islam in order to build multicultural inclusion need to study in-depth studies, with curriculum review movements at various levels of education. Researchers use the type of literature study research method that is gathering information relevant to the topic that is the object of research. The results or conclusions from this research are effective efforts in building the deradicalization of religion with educational institutions, through the reorientation of the vision of religious education based exclusively on monopoly toward the use of multicultural inclusion.
\end{abstract}

Keywords: religious deradicalisation, inclusive-multicultural education

\section{Pendahuluan}

Indonesia merupakan salah satu negara multikultural terbesar di dunia, yang terdiri dari 17.504 pulau. Sekitar 11 ribu pulau dihuni oleh penduduk dengan 359 sukudan 726 bahasa, ${ }^{1}$ dan enam agama. Indonesia merupakan negara yang dapat dikatakan kurang mampu dalam mengelola kemajemukan dengan baik, dibuktikan dengan maraknya aksi terororisme dan radikalisme Islam di Indonesia. Banyak nya kasus pengeboman seperti kasus bom gereja III di Surabaya pada tahun 2018, kasus bom bunuh diri di Polrestabes Medan tahun 2019, selain kasus terorisme yang dijelaskna tersebut, radikalisme Islam juga merebak dimana-mana, seperti kasus Islam yang terjadi di Jemaat Ahmadiyah di Cikusik, ${ }^{2}$ terdapat kasus

${ }^{1}$ M.Ainul Yaqin, Pendidikan Multikultural (Yogyakarta: Pilar Media, 2005),4.

2 Indriyani Ma'rifah, "RekonstruksiPendidikan Agama Islam : Sebuah Upaya Membangun Kesadaran Multikultural untuk Mereduksi Terorisme dan Radikalisme Islam ", AICIS, 5 (November, 2012), 22. 


\section{AL-ADABIYAH: Jurnal Pendidikan Agama Islam}

terbaru tentang radikalisme yaitu kasus penusukan Wiranto pada tahun 2019, maraknya kasus radikalisme dan terorisme tidak dapat terpisah dengan Islam akibatnya sedikit orang memiliki pandangan bahwa umat Islam meruakan salah satu pihak yang dipersalahkan. Ajaran Islam menjadi sasaran tuduhan sebagai sumber utama terjadinga kekerasan atas nama agama. Lembaga pendidikan Islam juga rmenjadi subyek yang memperoleh tuduhan, lembaga pendidikan Islam merupakan lembaga temapat berlang-sungnya pendidikan yang berkarakteristik Islam yang dilaksanakan dengan tujuan untuk mengubah tingah laku individu kearah yang lebih baik melalui interaki dengan lingkungan.

Pendidikan saat ini memiliki peluang menjadi penyebaran bibit radikalisme dan sekaligus pangkal Islam radikalisme. Dengan menjamurnya ormas pasca reformasi, pendidikan diangap menjadi pintu bagi penyebaran dakwah Islam. Oleh sebab itu lahirlah pendidikan Islam yang didirikan diberbagai jenjang pendidikan, yang dimanfaatkan untuk membangkitkan kesadaran inklusif-multikulultural.

Berdasarkan penelitian yang dilakukan oleh lembaga kajian Islam dan perdamaian, pada bulan oktober 2010 hingga 2011 menunjukan bahwa 49\% siswa seruju dengan aksi radikalisme demi agama. ${ }^{3}$ Dari fenomena tersebut maka terdapat kesimpulan bahwa pendidikan agama Islam selama ini lebih bercorak eksklusif ketimbang inkluivistik, maksudnya pengajaran pendidikan Islam menonjolkan pada kebenara agama sendiri dan beranggapan agamanya sebagai satu-satu nya jalan keselamatan. Oleh sebab itu, pendidikan Islam di Indonesia perlu diperbaiki dalam menumbuhkan kesadaran Inklusif-Multikultural. Dari paparan diatas peneliti ingin mengkaji mengenai upaya deradikalisasi untuk meminimalisir radikalisme Islam dalam rangka membangun kesadaran inklusifmultikultural. Oleh sebab itu peneliti menggunakan judul Membangun Kesadaran inklusif-Muktikultural Untuk Deradikalisasi Pendidikan Islam.

3 Ibid., 22. 


\section{Tinjauan Literatur}

\section{Islam Inklusif-multikultral dalam teori Gestalt}

Pendidikan inklusif lahir sebagai jawaban dari adanya sikap eksklusifisme yaitu paham yang mendorong munculnya sikap dan karakter fundamentalis radikalis, agresif bahkan teroris. Sikap eksklusifisme dalam melihat pertikaian dan pluralitas tidak hanya akan merugikan orang lain, dan merugikan diri sendiri, oleh karena itu pendidikan Islam inklusif hadir sebagai rivalitas terhadap eksklusifisme yang tentunya mempunyai konsepsi berbeda. Pendidikan Islam inklusif multikultural dalam perspektif teori Gestalt. ${ }^{4}$ Konsep tentang kesadaran menurut teori gestalt yaitu proses penyembuhan dan sebagai dasar dari pengetahuan dan komunikasi, apabila individu berada dalam kesadaran maka individu tersebut dapat mengatur diri dalam lingkungannya.

Pandangan inklusifmultikultural jika dilihat dari kacamata perspektif teori Gestalt dapat dijelaskan yaitu diperlukan pola baru yang inklusifmultikultural memerlukan cara baru dalam lingkup hubungan di antara epistemologi Islam. Ketiga epistemologi pendidikan Islam sesperti bayani, burhani dan irfani seharusnya tidak berdiri sendiri, dan saling membenarkan atas kebenaran masing-masing, tetapi bersinergi dan berdialog dengan baik agar saling mengisi dan melengkapi kekurangan dari masing-masing epistemologi yang ada.

Pembaharuan epistemologi ini bertujuan agar hubungan di antara ketiga epistimologi tersebut lebih sesuai dengan keadaan sosial-budaya yang berkembang. Maksudnya, berpatokan pada ijtihad dan tajdid, epistemologi pendidikan Islam memerlukan perpaduan secara sinergis-dialektis antara tiga sistem epistemik pemikiran Islam (bayani, burhani dan irfani) di dalam struktur hierarkis-piramidal yang bermatra ayat kauniyah dan ayat qauliyah dalam kerangka humanisasi, liberasi dan transendensi. ${ }^{5}$

${ }^{4}$ Muhammad Yusuf, Pendidikan Inklusif-Multikultural Dalam Perspektif Teori Gesalt, (t.tp: SMA Negeri 1 Paket Tulungagung, 2014), 197

5 Syaiful Sagala, Konsep Dan Makna Pembelajaran, (Bandung: Alfabeta, 2003) 


\section{AL-ADABIYAH: Jurnal Pendidikan Agama Islam}

Ketiga epistemologi yang ada sebaiknya dapat berdialog dan berjalan beriringan. Pola pikir bayani dapat bekembang jika diadakannya dialog, dapat memahami dan mengambil manfaat dari sisi-sisi fundamental yang berdasarkan pola pikir irfani dan burhani. Sebab itu, hubungan yang baik antara ketiga epistemologi tersebut tidak dalam bentuk pararel ataupun linier melainkan dalam bentuk sirkular. Bentuk pararel dapat melahirkan corak epistemologi yang berjalan masing-masing tanpa adanya hubungan dan persentuhan antara satu dengan yang lain. Sedangkan bentuk linier berasumsi bahwa salah satu konsep dari ketiga epistemologi menjadi "primadona". Oleh sebab itu sangat tergantung pada sedangkan pada bentuk sirkular diharapkan masing-masing corak epistemologi dalam Islam dapat memahami kekurangan dan kelebihan masing-masing sehingga akan mengambil manfaat dari temuan-temuan yang dilakukan oleh tradisi keilmuan lain dalam hal memperbaiki kekurangan yang ada.

Bentuk sirkular yang dapat menjadi pioner bagi pembaharuan pendidikan Islam yang lebih bersifat inklusif-multikultural, dengan hubungan sirkular tersebut ketiga ranah epistemologi Islam, corak keilmuan Islam akan lebih bersifat komprehensif, luas, dan inklusif, pada lingkup kehidupan yang beragam, penuh dengan keberagaman identitas, baik multietnis, multibahasa, multireligi, multiras dan multikultural. Pendidikan Islam mampu menuju perkembangan pendidikan yang lebih baik dan bersifat adaptif, maju dan kompetitif dalam bentuk perkembangan dan perubahan zaman. Apabila bentuk sirkular dan integratif pada epistemologi bayani, burhani dan irfani dapat di implementasikan, maka model pendidikan Islam yang bersifat bayani seperti fikih, ibadah, kalam/ aqidah/ tauhid, tafsir, hadis, tarikh, akhlak, tidak lagi steril dari perjumpaan, persinggungan dan pergumulannya dengan disiplin keilmuan lain di luar dirinya.

Model pendidikan Islam yang berwawasan bayani akan bersatu dan berdialog dengan keilmuan burhani dan irfani dalam menjawab masalah kehidupan masyarakat modern yang yang sifatnya lebih plural dan multikultural. Oleh sebab itu pendekatan burhani yang berwawasan 


\section{AL-ADABIYAH: Jurnal Pendidikan Agama Islam}

filsafat keilmuan, pendekatan sosiologi, antropologi, psikologi, sains serta ilmu pengetahuan kontemporer lainnya juga dapat digunakan sebagai pisau bedah yang bersamaan dengan pendekatan bayani guna mengatasi masalah masyarakat modern. Pendekatan irfani juga ikut terlibat mendampingi corak keilmuan bayani dan burhani dengan menyumbangkan ruh keilmuan Islam sehingga tidak gersang dari nilai-nilai akhlak, humanities dan keIslam an dalam keilmuannya. Dengan pendekatan irfani, akan memunculkan logika spiritual yang dapat mengantarkan para pelaku pendidikan seperti guru, kepala sekolah, pengawas, anak didik dan lainnya, untuk lebih memiliki sikap simpati, empati, emotional quotient dan spiritual quotient, ${ }^{6}$ sehingga mereka dapat hidup dengan baik dalam lingkungan yang plural dan multikultural.

Dalam kaitannya dengan peran pendidikan Islam yaitu pendidikan Islam sangatlah penting dalam membangun world view peserta didik untuk mampu melakukan kajian keagamaan yang sifatnya universalitas dan tidak terjebak dalam subjektivitas sehingga akan mampu membangun sikap inklusif dan menghindari sikap ekslusif, oleh karena itu pendidikan inklusif multikultural sangat diperlukan, sehingga akan membasmi bibit bibit fundamentalisme, radikalisme, agresifisme, mudahnya muncul klaim takfir yang mengakibatkan konflik anatar agama bahkan terorisme yang sering dialamatkan karena kesalahan pendidikan Islam. Dalam mengimplementasikan pandangan keagamaan yang inklusif multikultural, semua golongan harus memahami serta menyadari bahwa diluar kelompok mereka mempunyai berbagai jenis entitas yang berbeda, serta memiliki pandangn dan penafsiran yang berbeda, dan perbedaan tersebut harusnya di hargai dan dihormati keberadaannya. Kesadaran yan seperti ini yang akan membimbing setiap golongan untuk tidak merasa benar, dan menyalahkan pamdangan orang lain yang berbeda dengan dirinya serta meniadakan eksistensi golongan lain.

${ }^{6}$ Ngainun Naim dan Achmad Sauqi, Pendidikann Multikultural: Konsep Dan Aplikasi, (Yogyakarta: Ar Ruzz Group, 2008), 176. 


\section{Deradikalisasi Pendidikan Islam}

Deradikalisasi yaitu usaha sistematis yang dapat membangun kesadaran amsyarakat, bahwa fanatisme sempit, fundamentalis, dan radikalisme berpotensi membangkitkan terorisme. ${ }^{7}$ Sedangkan menurut BNPT yaitu segala upaya untuk menetralisir paham-paham radikal melalui pendekatan interdisipliner seperti, hukum, hukum, psikologi, agama dan sosial budaya bagi mereka yang dipengaruhi paham radikal atau paham yang menganut kekerasan. ${ }^{8}$ Sedangkan dalam lingkup terorisme yang muncul akibat paham keberagamaan radikal, deradikalisasi dapat diartikan sebagai proses untuk membenarkan pemahaman keagamaan yang sempit, mendasar, menjadi moderat, luas dan komprehensif. ${ }^{9}$

Deradikalisasi dapat pula difahami sebagai salah satu upaya utuk menetralisasi faham faham radikal dengan cara pendekatan interdisipliner, seperti agama, psikologi, hukum, serta sosiologi yang ditujukan bagi mereka yang dipengaruhi oleh faham radikal. Deradikaliasi ini meliputi, banyak program yang terdiri dari reorientasi motivasi, redukasi, resosialisasi, serta mengupayakan kesejahteraan sosial dan kesetaraan dengan masyarakat lain bagi mereka yang terlibat dengn tindak pidana terorisme. ${ }^{10}$ Dalam perspektif Ahmad Asroni beberapa cara yang dapat ditempuh untuk mengahsilkan pendidik yang inklusif multikultural, pertama menyelanggarakan berbagai training, workshop, seminar, dan kegiatan lainnya. Kedua menyelanggarakan dialog keagamaan dengan pendidik agama pemuka atau umat beragama lainnya. Ketiga memperkenalkan

7 Masduqi, "Deradikalisasi Pendidikan Islam Berbasis Khazanah Pesantren", Pesantren Assalafiyyah Mlangi Yogyakarta (2013), 12.

8 Petrus Golose, Deradikalisasi Terorisme, Humanis, Soul Approach dan Menyentuh Akar Rumput, (Jakarta : Yayasan Pengembangan Kajian Ilmu Kepolisian, 2009), 62.

9 Amirsyah, Meluruskan Salah Paham Terhadap Deradikalisasi Pemikiran, Konsepdan Srategi Pelaksanaan, (Jakarta: Gravindo Khazanah Ilmu, 2012), 35.

10 Ibid., 13 


\section{AL-ADABIYAH: Jurnal Pendidikan Agama Islam}

bacaan bacaan atau berbagai referensi yang bernuansa pendidikan multikultural sejak dini kepada para pendidik. ${ }^{11}$

\section{Metode}

Peneliti menggunakan metode penelitian kualitatif dengan jenis kajian kepustakaan. Metode kepustakaan yaitu tehnik pengumpulan data dengan melakukan penelaah terhadap berbagai buku, litetur, catatan, serta berbagai laporan yang berkaitan dengan masalah yang ingin di pecahkan. ${ }^{12}$ Dalam penelitian ini menggunakan teknik dokumenter. Serta analisis data dengan menggunakan konten analisis yaitu sebuah teknik yang diguakan untuk menganalisis dan memahami teks.

\section{Hasil dan Diskusi}

\section{Karakteristk radikalisme Islam}

Pengertian radikal berawal dari bahasa latin "radix" yang artinya akar. Dalam bahasa Inggris kata radical memiliki arti ekstrim, menyeluruh, radikal, revolusioner, ultra dan fundamental. Sedangkan radicalism artinya doktrin atau praktik penganut paham radikal atau paham ekstrim. ${ }^{13}$

Radikalisme Islam yang ada di Indonesia adalah bentuk kenyataan sosial dan sejarah di dalam negara yang majemuk. Supaya tidak menjadi ancaman untuk kehidupan masa depan multikulutralis di Indonesia maka diperlukan usaha gerakan deradikalisasi bagi umat agama Islam dengan perluasan gerakan Islam yang moderat, pluralis, dan inklusif di dalam masyarakat dan pendidikan multikultural terhadap lembaga pandidikan. Radikalisme bisa dipahami sebagai salah satu sikap yang mengimpikan perubahan terhadap status quo dengan jalan penghancuran secara total,

11 Masduqi, Deradikalisasi Pendidikan Islam Berbasis Khazanah Pesantren, Pesantren Assalafiyyah Mlangi Yogyakarta, (2013), 12.

12 Mestika Zed, Metode Penelitian Kepustakaan, (Indonesi, Jakarta: 2008), 150.

13 M. Nuhrison, "Faktor-FaktorPenyebabMunculnyaFaham/Gerakan Islam Radikal di Indonesia”, HARMONI Jurnal Multikultural \&Multireligius, 31 (2009), 36. 


\section{AL-ADABIYAH: Jurnal Pendidikan Agama Islam}

dan digantikan dengan sesuatu yang baru dan berbeda. ${ }^{14}$ Biasanya upaya yang dilakukan bersifat revolusioner, yaitu merubah nilai-nilai yang terdapat dengan drastis serta dengan kekerasan (violence) dan aksi-aksi yang ekstrem. ${ }^{15}$ Radikalisme terdapat pada pemeluk agama, yaitu agama Islam . Upaya sederhana radikalisme Islam dapat dimaknai sebagai segala tingkah laku yang fanatik dalam agama.

Radikalisme di dalam pendidikan mempunyai pengaruh ancaman yang berbahaya dalam mengadakan kelangsungan kualitas pendidikan. Radikalisme bisa muncul kapan saja, dari mana saja dan dapat dilakukan siapa saja. Oleh sebab itu radikalisme perlu disikapi secara utuh dan komprehensif. Wujud prasangka pada buku-buku teks terwujud dalam bentuk kesalahan pendapat atau kegiatan ibadah yang berbeda. Memperkenalkan pendapat yang satu tanpa mengadakan pendapat lainnya. Mengandung pandangan negatif atau stereotip tentang umat lain tanpa memperkuat Islam, menghormati kebebasan berkeyakinan serta tanpa menegaskan bahwa antar umat beragama harus rukun serta secara sosial harus bahu membahu sebagaimana Islam ajarkan. ${ }^{16}$

Kelompok radikal memiliki ciri-ciri antara lain; pertama, sering menuntut kebenaran tunggal dan menyesatkan kelompok lain yang tak sependapat. Tuntutan kebenaran selalu muncul melalui kalangan yang seakan-akan mereka adalah Nabi yang tak pernah melakukan kesalahan (ma'sum), padahal mereka hanya manusia biasa. Tuntutan kebenaran tidak dapat dibenarkan di karena manusia hanya mempunyai kebenaran yang mutlak serta hanya Allah yang tahu kebenaran absolut. Oleh skarena itu, jika terdapat kelompok yang merasa paling benar maka secara otomatis mereka telah melakukan tindakan congkak merebut otoritas Allah.

14 Marx Juergensmeyer, "TerorAtasNamaTuhan: Kebangkitan Global Kekerasan Agama", Nizampress, (2002), 50.

15 Ibid., 30. 163.

16 M. Saekan Muchid, Radikalisme dalam Dunia Pendidikan, (Kudus: STAIN, 2016), 


\section{AL-ADABIYAH: Jurnal Pendidikan Agama Islam}

Kedua, radikalisme dianggap mempersulit agama Islam yang sejatinya samhah (ringan) yang beranggapan bahwa ibadah sunnah ibadah wajib dan makruh seakan-akan haram. Karakter radialisme yaitu perilaku beragama yang lebih mengutamakan persoalan-persoalan sekunder dan mengabaikan yang primer. Contohnya adalah kejadian memanjangkan jenggot serta membuat celana di posisi diatas mata kaki. Umat Islam seyogianya memprioritaskan kewajiban ketimbang hal-hal sunnah yang sepele.

Ketiga, kelompok radikal bersifat berlebihan dalam beragama yang berada tidak pada tempatnya. Didalam berdakwah mereka melupakan metode gradual yang digunakan oleh Nabi, sehingga akibatnya dakwah mereka lebih membuat umat Islam yang masih tidak mengerti merasa ketakutan dan keberatan. Padahal QS. 2:185 sudah menjelaskan bahwa Allah menginginkan hal-hal yang meringankan dan tidak menginginkan halhal yang memberatkan umat-Nya.

Keempat, agresif dalam berinteraksi, lantang dalam berbicara dan emosional dalam berdakwah. Ciri-ciri dakwah seperti ini sangat bertolakbelakang dengan kesantunan dan kelembutan dakwah Nabi dalam QS. 3:159. Dalam QS. 16:12 Allah juga menganjurkan umat Islam supaya berdakwah dengan cara yang santun dan menghindari kata-kata kasar. Anjuran yang senada datang dari sabda Rasulullah SAW: "Sesungguhnya Allah mencintai kelembutan dalam segala hal" dan "Kelembutan tidak masuk dalam sebuah hal kecuali membuatnya indah sedangkan kekerasan tidak masuk dalam sebuah hal kecuali hanya akan memperburuknya". ${ }^{17}$

Kelima, kelompok radikal mudah berprasangka buruk kepada orang lain di luar kelompoknya. Mereka sering memandang orang lain dari aspek negatifnya saja dan mengabaikan aspek positifnya. Hal ini harus ditinggalkan oleh umat Islam, karena sebab radikalisme yaitu berprasanga busruk kepada orang lain. Berburuk sangka ialah wujud sikap

17 Yusuf Qordawi, al-Shahwah al-Islam iyah bayn al-Juhud wa al-Tatamu, (Ciro: Bank Al takwa, 140H), 33. 


\section{AL-ADABIYAH: Jurnal Pendidikan Agama Islam}

merendahkan orang lain. Kelompok radikal selalu terlihat merasa suci dan beranggapan kelompok lain sebagai ahli bid'ah dan sesat.

Keenam, mudah mengkafirkan orang lain yang berbeda pendapat. Pada masa klasik sikap seperti hal tersebut sama dengan golongan Khawarij, lalu di masa kontemporer sama dengan Jamaah Takfir wa alHijrah dan kelompok-kelompok puritan. Kelompok ini mengkafirkan orang lain yang telah berperilaku maksiat, mengkafirkan pemerintah yang berideologi demokrasi, mengkafirkan rakyat yang rela tmengikuti penerapan demokrasi, mengkafirkan umat Islam di Indonesia yang menjunjung tradisi lokal, dan mengkafirkan semua orang yang memiliki pandangan berbeda dengan mereka sebab mereka yakin bahwa pendapat mereka adalah pendapat Allah. Penerapan syariat yang dibicarakan oleh kelompokkelompok radikal lebih sering menyentuh persoalan aurat, dan peratusran daerah syariat yang dibedakan. Penerapan syariat jarang menyuarakan isuisu pembelaan terhadap kaum minoritas dan lemah yang teraniaya, pembelaan

terhadap agama non-Muslim yang dihalang-halangi kebebasan dalam beribadah, rekonsiliasi konflik antar Sunni-Syiah, pembelaan kepada nasib buruh dan petani, ekonomi kerakyatan serta isu-isu lain yang berpengaruh dengan kesejahteraan sosial. Penerapan syariat yang hanya berhubungan dengan persoalan-persoalan sekunder yang dijadikan fungsi agama sebagai pembelenggu dan bukan sebagai teologi pembebasan sosial.

Menurut Yusuf al-Qardhawi, solusi-solusi untuk memecahkan masalah radikalisme yaitu:

a. menghargai kemauan kalangan Islam radikalis menggunakan cara yang terbuka dan demokratis;

b. memprioritaskan mereka secara manusiawi dan penuh persaudaraan;

c. tidak melawan mereka dengan sikap yang sama-sama ekstrem dan radikal. Artinya, kalangan radikal ekstrem dan kalangan sekular ekstrem harus ditarik ke posisi moderat agar berbagai kepentingan dapat dikompromikan; 


\section{AL-ADABIYAH: Jurnal Pendidikan Agama Islam}

d. dibutuhkan masyarakat yang mngutarakan kebebasan berpikir untuk semua kelompok sehingga dapat mewujudkan dialog yang sehat dan saling mengkritik yang konstruktif seerta empatik antar aliran-aliran;

e. menjauhi sikap saling mengkafirkan dan tidak membalas pengkafiran dengan pengkafiran;

f. mempelajari agama secara benar sesuai dengan metode metode yang sudah ditentukan oleh para kiai Islam dan mendalami esensi agama agar menjadi Muslim yang bijaksana;

g. tidak memahami Islam secara parsial dan reduktif. Caranya adalah dengan mempelajari esensi tujuan syariat (maqashid syari'ah).

Dengan mengamalkan esensinya, maka umat Islam tidak akan terikat pada hal-hal yang bersifat simbolis. Atribut jubah dan celana di atas mata kaki adalah contoh pemahaman agama yang simbolis. Sejatinya Nabi tidak pernah menentukan jenis-jenis pakaian, tetapi Nabi memakai berbagai model pakaian yang simpel dan fleksibel.

\section{Pendidikan Inklusisf dan Toleran dalam Pendidikan}

Pendidikan toleran dan inklusif saat ini sangat mendesak untuk diterapkan di pesantren dan lembaga pendidikan Islam lainnya di tengahtengah maraknya indoktrinasi. Pendidikan inklusif merupakan proses belajar mengajar yang mengedepankan keterbukaan dalam menyikapi perbedaan pendapat. Hal ini terinspirasi dari statement Imam al-Syafi'i (w. 204 H), pendiri madzhab Syafi'iyyah: "Pendapatku benar tetapi mungkin salah sedangkan pendapat orang lain salah tetapi mungkin benar" (ra'yi sawabun yahtamilu al-khata'a wa ra'yu ghayri khata'un yahtamilu alsawaba).

Dengan prinsip ini, Imam al-Syafi'i di satu sisi berusaha terhindar dari dogmatisme dan absolutisme yang menganggap bahwa dirinya sendiri adalah yang benar sedangkan orang lain pasti salah. Di sisi lain, Imam alSyafi'i berusaha menyingkir dari jebakan-jebakan relativisme yang 


\section{AL-ADABIYAH: Jurnal Pendidikan Agama Islam}

membenarkan semua pendapat tergantung perspektif masing-masing. Ajaran toleran dan moderat ala Imam al-Syafi'i memberi inspirasi kepada kita bahwa "penyesatan" terhadap orang yang berbeda pendapat adalah tindakan yang tidak setis.

Pendidikan toleran dan inklusif harus dibangun pula di atas karakter anak didik yang mengendepankan kerendahan hati, kemurahan hati, keramahan, dan kesopanan dalam menghargai orang lain, sedangkan pendidikan doktriner dan intoleran sejatinya terbangun di atas sifat keangkuhan yang menghancurkan apa saja yang tidak dipahami dan yang berbeda. Alih-alih menjunjung tinggi dialog yang simpatik, pendidikan doktriner dan intoleran justru mengajarkan kepada para anak didik agar menafikan perbedaan yang disebabkan oleh faktor fanatisme terhadap satu pandangan yang diterima secara benar. Pendidikan toleran dan inklusif merupakan hasil dari sikap yang sederhana, yakni kritik diri (self-critical) atas keterbatasan pemahaman manusia. Seorang pendidik yang toleran dan inklusif harus mencontohkan bahwa ia tidak takut untuk mengakui kebodohan atau ketidakpastian pendapatnya sendiri.

Upaya mewujudkan pendidikan toleran dan inklusif menghadapi problem berupa mengakarnya teologi intoleransi dan eksklusivitas terutama berkaitan dengan isu-isu pertikaian antar sekte yang saling mengkafirkan. Pengkafiran tersebut selalu dipicu oleh klaim kebenaran yang bertendensi pada bunyi harfiyah hadis Nabi tentang terpecahnya umat Islam menjadi tujuh puluh tiga sekte tetapi yang masuk surga hanya satu. Akhirnya masing-masing sekte mengklaim paling berhak masuk surga sementara sekte yang lain masuk neraka. Ini adalah problem pendidikan Islam yang terjadi di lembaga-lembaga Islam pada umumnya. Untuk menanggulanginya, nalar eksklusif ini harus dilenturkan dengan cara kembali kepada prinsip al-Quran bahwa surga dan neraka tidak dimonopoli oleh sekte tertentu.

Yang perlu dimengerti, pendidikan Islam yang toleran dan inklusif tidak hendak mendidik para murid untuk menjadi apatis dan mentolelir problem sosial. Pendidikan Islam yang toleran dan inklusif tetap harus 


\section{AL-ADABIYAH: Jurnal Pendidikan Agama Islam}

dibangun di atas budaya kritis di mana anak didik berhak menegur dan menasehati apabila ada anggota masyarakat yang merusak kode etik sosial. Para pelajar Islam yang toleran dan inklusif bukan berarti orang-orang yang acuh terhadap masalah-masalah sosial. Mereka tetap bertanggungjawab membantu kontrol sosial melalui amar ma'ruf nahi munkar yang dianjurkan dalam al-Quran (QS. 103: 2-3).

\section{Pendidikan Islam Inklusif-Multikultural}

Dalam hal ini, yang perlu mendapat perhatian adalah faktor kurikulum, pendidik, serta strategi pembelajaran yang digunakan oleh guru. Hal ini tidak berarti bahwa faktor lain kurang penting, melainkan ketiga hal tersebut yang dapat menempati prioritas Perumusan kurikulum pendidikan Islam yang berwawasan toleransi yang merupakan langkah mendesak yang harus dilakukan. Sebab, dewasa ini eskalasi kekerasan berbasis agama kian meningkat. Keberadaan kurikulum pendidikan Islam mempunyai nilai-nilai toleransi yang menjadi bagian yang penting sebab menjadi tuntutan bagi guru dalam penyampaian materi-materi tentang ajaran Islam yang menghargai keragaman dan perbedaan. ${ }^{18}$

Perlunya perimbangan antara materi yang berupa teks dan konteks. Sehingga teks yang berisi ajaran normatif masih bersifat umum, sementara konteks berupa realitas empirik-faktual yang bersifat partikular. Persoalan seringkali muncul ketika teks berhadapan dengan realitas partikular yang heterogen tersebut. Karena itu, materi pelajaran harus berisi realitas yang dapat dihadapi peserta didik dalam kehidupan sehari-hari. Disamping itu, meskipun materi yang diberikan mengandung teks-teks normatif, namun ia juga harus berisikan kasus-kasus yang konkrit di masyarakat sehingga anak sadar bahwa ia hidup dalam situasi nyata yang penuh perbedaan. Dengan demikian guru agama Islam dan guru lainnya dapat berbaur serta mengenal satu sama lain, sehingga akan melahirkan sikap toleransi dan

18 Muqowim, Mencari Pola Pendidikan Agama Dalam Perspektif Multikultual, (MDC Jatim, 2004), 8. 


\section{AL-ADABIYAH: Jurnal Pendidikan Agama Islam}

apresiatif terhadap agama lain dan mengenalkan tulisan multikultural sejak dini kepada para pendidik.

Pendidik dan sekolah mempunyai peranan penting dalam menerapkan nilai-nilai keberagamaan yang inklusif dan moderat di sekolah. Apabila guru memiliki pandangan pemahaman keberagamaan yang inklusif dan moderat, maka ia juga dapat mengajarkan dan menerapkan nilai-nilai keberagamaan tersebut pada siswa di sekolah. Peran guru dalam hal ini meliputi:

a. seorang guru harus mampu bersikap demokratis, baik dalam sikap maupun perkataannya tidak diskriminatif.

b. pendidik harus memiliki kepedulian yang tinggi terhadap fenomena fenomena yang ada hubungannya dengan agama. Misalnya, ketika terjadi bom Gereja 3 di Surabaya tahun 2018, makaka tugas seorang guru yang berwawasan multikultural harus mampu menjelaskan kepeduliannya terhadap peristiwa tersebut.

c. gur seharusnya menjelaskan bahwa inti dari ajaran agama adalah menciptakan kedamaian dan kesejahteraan bagi seluruh umat manusia, maka pemboman, invasi militer, dan segala bentuk kekerasan adalah sesuatu yang dilarang oleh agama.

d. guru dapat memberikan konstruksi tentang pentingnya dialog dan musyawarah dalam menyelesaikan berbagai permasalahan yang berhubungan dengan keragaman budaya, etnis, dan agama (aliran), conntohnya, kasus penyerbuan dan pengusiran Jamaah Ahmadiyah di Lombok-NTB dan kekerasan pada jamaah Syiah di Sampang Madura, jika wacana inklusivisme beragama ditanamkan pada semua elemen masyarakat termasuk peserta didik. ${ }^{19}$

\section{Kesimpulan}

Terdapat tiga karakteristik radikalisme seperti: melakukan penolakan, memiliki keyakinan kuat terhadap suatu paham, tidak peduli pada HAM.

19 Husniyatus, Pendidikan Multikultual: Upaya Membangun Keberagaman Inklisif di Sekolah, (ISLAMICA, 2007), 141. 


\section{AL-ADABIYAH: Jurnal Pendidikan Agama Islam}

Terdapat lima cara yang dapat dilakukan untuk membangun kesadaran inklusif-multikultural: (1) kaum muslimin perlu menyadari bahwa perbedaan ialah keniscayaan yang tidak dapat dipungkiri lagi; (2) perbedaan umat Islam adalah rahmat dan bentuk kekayaan kebudayaan Islam yang justru akan membuat kaum Muslimin semakin dinamis dan leluasa menentukan pilihan pendapatnya; (3) kaum Muslimin berusaha memilih pendapat yang moderat, sebab di dalam khazanah keilmuan Islam terdapat pendapat-pendapat ulama yang keras yang sebaiknya dijauhi; (4) menjauhi sikap mengklaim kebenaran sepihak; (5) saling tolong-menolong berbagai masalah yang telah disepakati oleh semua golongan; (6) toleransi dalam masalah-masalah yang diperselisihkan oleh ulama.

\section{Referensi}

Abbas, Nasir, "Berdayakan Potensi Masyarakat dalam Pemberantasan Terorisme", Komunika, 12 (VII) Juli 2011:5

Al-Qardhawi, Yusuf, al-Shahwah al-Islam iyah bayn al-Juhud wa al-Tatamu. Cairo: Bank al-Taqwa, $1406 \mathrm{H}$.

Juergensmeyer, Marx, Teror Atas Nama Tuhan: Kebangkitan Global Kekerasan Agama, Jakarta-Magelang: Nizam Press \& Anima Publising: 2002.

Ma'rifah, Indriyani, "RekonstruksiPendidikan Agama Islam : Sebuah Upaya Membangun Kesadaran Multikultural untuk Mereduksi Terorisme dan Radikalisme Islam," Conference Proceedings Annual International Conference on Islamic Studies (AICIS) XII IAIN SunanAmpel Surabaya 5-8 November 2012: 22

Ma'rifah, Indriyani, "RekonstruksiPendidikan Agama Islam : Sebuah Upaya Membangun Kesadaran Multikultural untuk Mereduksi Terorisme dan Radikalisme Islam," Conference Proceedings Annual International Conference on Islamic Studies (AICIS) XII IAIN SunanAmpel Surabaya 5-8 November 2012: 22

Maduqi, "Deradikalisasi Pendidikan Islam Berbasis Khazanah Pesantren," Pesantren Assalafiyyah Mlangi Yogyakarta 2013: 12

Mubarok, Husni, "Memahami Kembali Arti Keragaman: Dimensi Eksistensial, Sosial dan Institusional", HARMONI Jurnal Multikultural \& Multireligius, IX (35) Juli-September 2010: 3 
Muchith, M. Saekan. "Radikalisme dalam Dunia Pendidikan", Addin, Vol. 10 No. 102016.

Muqowim, " Mencari Pola Pendidikan Agama Dalam Perspektif Multikultual”, MDC Jatim, I (3) Tahun II, Oktober 2004: 8

Nuh, Nuhrison M., "Faktor-FaktorPenyebabMunculnyaFaham/Gerakan Islam Radikal di Indonesia”, HARMONI Jurnal Multikultural \& Multireligius, VIII (31) Juli-September 2009: 3614

Yaqin, M. Ainul, Pendidikan Multikultural; Cross-Cultural Understanding untuk Demokrasi dan Keadilan, Yogyakarta: Pilar Media, 2005.

Yusuf, Muhammad, "Pendidikan Inklusif- Multikultural Dalam Perspektif Teori Gesalt," SMA Negeri 1 Paket Tulungagung 2014.

Zainiyati, Husniyatus Salamah, "Pendidikan Multikultual: Upaya Membangun Keberagaman Inklisif di Sekolah", ISLAMICA, I (2), Maret 2007.

Zed, Mestika, Metode Penelitian Kepustakaan, Metode Penelitian Kepustakaan, Jakarta: Yayasan Obor Indonesia, 2008. 